\title{
Moderate glucose control results in less negative nitrogen balances in medical intensive care unit patients: a randomized, controlled study
}

\author{
Chien-Wei Hsu ${ }^{1,2^{*}}$, Shu-Fen Sun ${ }^{2,3}$, Shoa-Lin Lin ${ }^{1,2}$, Hsiu-Hua Huang ${ }^{4}$ and Kam-Fai Wong ${ }^{5}$
}

\begin{abstract}
Introduction: Hyperglycemia and protein loss are common in critically ill patients. Insulin can be used to lower blood glucose and inhibit proteolysis. The impact of moderate insulin therapy on protein metabolism in critically ill patients has not been evaluated. We compared urinary nitrogen excretion, nitrogen balance, serum albumin concentrations, prealbumin concentrations, and clinical outcomes between patients receiving moderate insulin therapy (MIT) and conventional insulin therapy (CIT) in a medical ICU.

Methods: Patients were randomly divided into groups and treated with MIT (glucose target 120 to $140 \mathrm{mg} / \mathrm{dl}$ ) or CIT (glucose target 180 to $200 \mathrm{mg} / \mathrm{dl}$ ). Calories and protein intake were recorded each day. On days 3, 7 and 14, the 24-hour urinary nitrogen excretion, nitrogen balance, and serum albumin and prealbumin concentrations were measured. Clinical outcomes data were collected.
\end{abstract}

Results: A total of 112 medical ICU patients were included, with 55 patients randomized to the MIT group and 57 patients randomized to the CIT group. Patients treated with MIT showed a trend towards increased nitrogen balance $(P=0.070)$, significantly lower urinary nitrogen excretion $(P=0.027)$, and higher serum albumin $(P=0.047)$ and prealbumin $(P=0.001)$ concentrations than patients treated with CIT. The differences between the two groups were most significant on day 3 , when all factors showed significant differences $(P<0.05)$.

Conclusions: Moderate glucose control results in less negative nitrogen balances in medical ICU patients. Differences are more significant in the early stages compared with the late stages of critical illness.

Trial registration: ClinicalTrial.Gov NCT 01227148

\section{Introduction}

Hyperglycemia, which is common in critically ill patients, occurs even in those patients who have not previously had diabetes $[1,2]$. Critical illness is associated with increased circulating concentrations of proinflammatory cytokines, such as TNF $\alpha$, IL-1, and IL-6, which may be important mediators of insulin resistance and hyperglycemia [3]. Altered glucose metabolism results from the release of counter-regulatory hormones. Epinephrine and cortisol oppose the normal action of insulin, leading to increased adipose tissue lipolysis and skeletal muscle proteolysis [4]. Reports state that

\footnotetext{
* Correspondence: cwhsu2003@yahoo.com

${ }^{1}$ Intensive Care Unit, Department of Medicine, Kaohsiung Veterans General Hospital, 386 Ta-Chung $1^{\text {st }}$ Road, Kaohsiung City 813, Taiwan

Full list of author information is available at the end of the article
}

pronounced hyperglycemia may lead to complications or a poor clinical outcome in such patients $[5,6]$. The maintenance of normoglycemia using insulin therapy has been shown to significantly reduce morbidity and mortality in critically ill patients $[5,7,8]$. However, some studies failed to demonstrate improved outcome [9-12], and even a higher mortality rate was found [13] Intensive insulin therapy has been associated with a significantly higher risk of hypoglycemia [5,7], resulting in concern regarding the safety of intensive insulin therapy. Glycemic control to a moderately tight range is not inferior to euglycemia and is clearly safer in critically ill patients [14]. Patients with glucose levels of $130 \mathrm{mg} / \mathrm{dl}$ were reported to have a significantly lower incidence of infection and sepsis and a lower mortality rate [15].

\section{C) Biomed Central}


Protein loss, which is also common in critically ill patients, is thought to arise from both increased proteolysis [16] and diminished protein synthesis [17]. Protein wasting can negatively affect patient outcome [18]. The use of insulin to promote an anabolic response during critical illness is a promising therapeutic approach. Animal studies have shown that strict insulin therapy normalizes organ nitrogen contents in diabetic rats [19]. Woolfson and colleagues demonstrated that insulin has important protein-sparing effects in severely ill trauma patients [20]. Shiozaki and colleagues showed that burn patients who received higher doses of insulin maintained a better nitrogen balance than a lower-dose group [21].

The purpose of this study was to investigate the differences in urinary nitrogen excretion, nitrogen balance, serum albumin and prealbumin concentrations, and clinical outcomes between moderate insulin therapy (MIT) and conventional insulin therapy (CIT) in critically ill patients.

\section{Materials and methods \\ Study design}

This study was a prospective, randomized, controlled trial conducted in an adult medical ICU of a tertiary medical center that has 1,235 beds in total, 59 of which are adult ICU beds. Trial and consent forms were approved by the Institutional Review Board of Kaohsiung Veterans General Hospital. The study was carried out between January 2006 and December 2006. Procedures were in accordance with the Helsinki Declaration.

\section{Subjects}

Patients aged 18 or over who were admitted to the medical ICU with blood glucose concentrations over 180 $\mathrm{mg} / \mathrm{dl}$ were eligible for inclusion. The criteria for exclusion included prior surgical treatment, pregnancy, participation in another study, patients with chronic renal loss, and patients who were expected to require treatment in the ICU for less than 4 days. Chronic renal loss was defined as persistent acute renal failure with the complete loss of kidney function for more than 4 weeks [22]. The first author (C-WH) enrolled participants. A total of 283 patients were evaluated and 171 patients were excluded. The remaining 112 patients were eligible for the study (Figure 1).

\section{Insulin therapy}

After informed consent was obtained from patients or the next of kin, patients were randomly assigned to receive either MIT or CIT using software-generated simple randomization procedures (computerized random number) without blocking. Except for the interventionists (nurses and doctors), patients and other staff members were not informed of the group assignments. In the MIT group, continuous insulin infusion was started when the blood glucose concentrations exceeded $140 \mathrm{mg} / \mathrm{dl}$ in order to maintain a blood glucose concentration between 120 and $140 \mathrm{mg} /$ dl. The insulin dose was adjusted using a neuro-fuzzy method; the insulin protocol is shown in Additional file 1 . In the CIT group, continuous insulin infusion was delivered when blood glucose concentrations exceeded $200 \mathrm{mg} / \mathrm{dl}$; the insulin dose was then adjusted to maintain a blood glucose concentration between 180 and $200 \mathrm{mg} / \mathrm{dl}$.

All patients were fed either intravenously (total parenteral nutrition) or enterally starting the day after ICU admission. Enteral feeding was attempted as early as possible at the discretion of the attending physician. Once enteral feeding was started, patients were administered full-strength isotonic commercial formula Jevity (Abbott Laboratories, Brockville, ON, Canada) commencing at $20 \mathrm{ml} /$ hour, and increased by $20 \mathrm{ml} /$ hour every 4 hours to satisfy energy and protein requirements recommended by the clinical dietitian following the Canadian clinical practice guidelines for critically ill patients [23]. All patients did not receive an albumin infusion during the study period.

\section{Data collection}

At the time of randomization, demographic data and clinical characteristics were obtained. Blood glucose concentrations were measured upon admission and, subsequently, every 1 to 4 hours in all patients. Baseline serum albumin concentrations, prealbumin concentrations (Hitachi 7600; Hitachi, Tokyo, Japan), serum creatinine, and 24-hour urinary urea nitrogen (UUN) levels were collected and evaluated after beginning the study, and these data were collected and evaluated on days 3, 7 , and 14 of the study. Additionally, we used full 24hour urine collection rather than spot urine samples to determine the UUN. Blood cultures were obtained whenever the central body temperature exceeded $38.5^{\circ} \mathrm{C}$ or other clinical signs of sepsis were present. Blood transfusions were conducted according to the protocol when hemoglobin levels decreased to below $7 \mathrm{~g} / \mathrm{dl}$ and were continued until target hemoglobin levels of 7 to 9 $\mathrm{g} / \mathrm{dl}$ were attained. A higher hemoglobin level was required in patients with special circumstances; for example, myocardial ischemia, severe hypoxemia, acute hemorrhage, or lactic acidosis [24].

From the time of randomization to the time of discharge from the ICU, daily caloric and protein intakes, all blood glucose measurements, doses of insulin, redblood-cell transfusions, blood cultures that were positive for pathogenic organisms, renal function, gastrointestinal bleeding, moderate hypoglycemia, and severe hypoglycemia were recorded. 


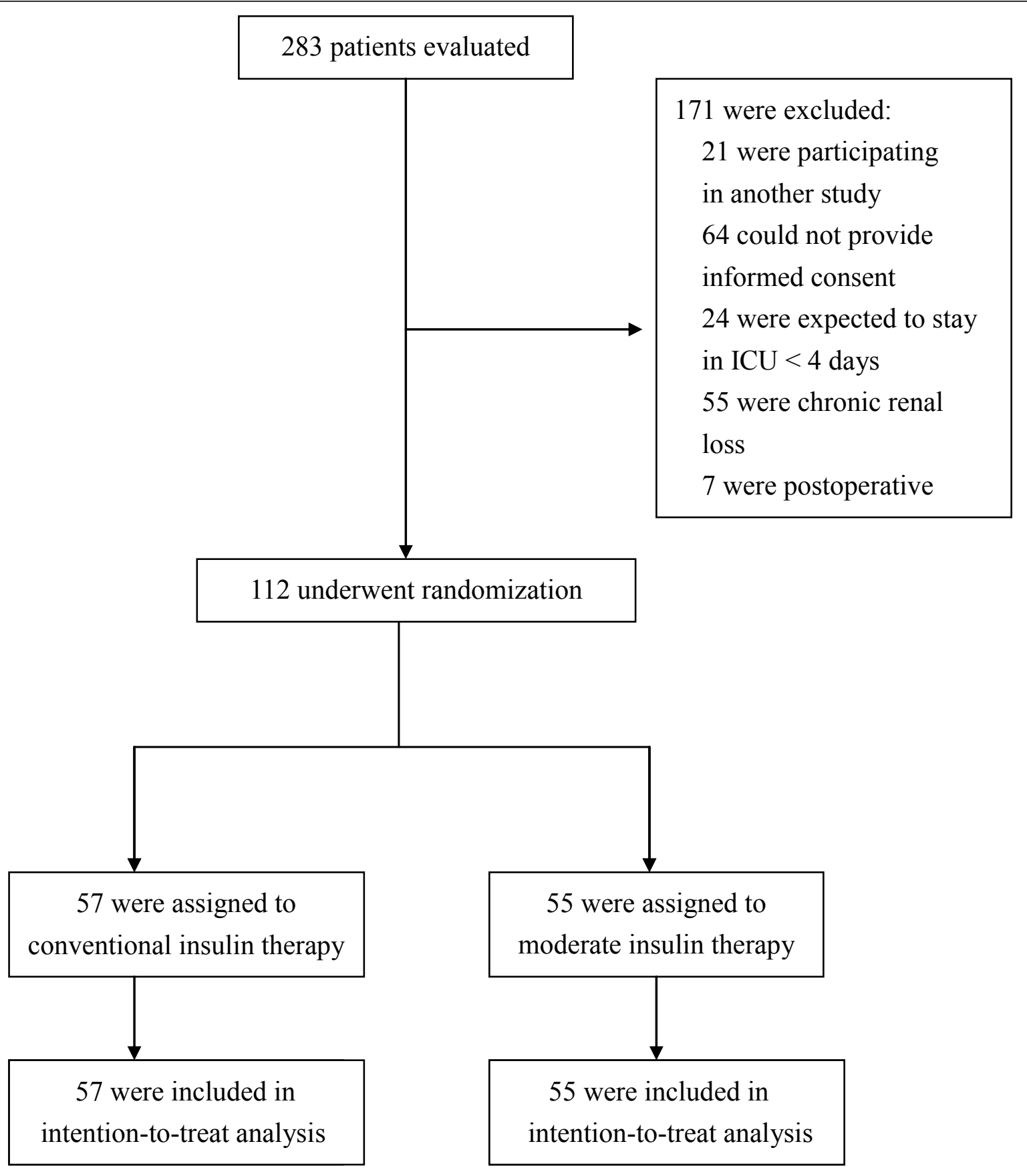

Figure 1 Assessment, randomization, and follow-up of the study patients. For detailed characteristics of randomized patients, see Table 1.

\section{Definitions}

Patients were classified as having diabetes on the basis of their medical history. Previous treatment with corticosteroids was defined as treatment with systemic corticosteroids for 72 hours or more immediately before randomization. Sepsis was defined by the presence of both infection and a systemic inflammatory response [25]. Acute renal injury was defined when serum creatinine concentrations increased by 2.0 times or the glomerular filtration rate decreased by more than $50 \%$ [22]. Creatinine clearance was calculated using the Cockcroft-Gault equation [26]:

$(140$ - age $($ years $)) \times$ body weight $(\mathrm{kg}) \times 0.85$ (if female) $/ 72 \times$ serum creatinine $(\mathrm{mg} / \mathrm{dl})$

Bloodstream infection was diagnosed either when a recognized pathogen was isolated from a blood culture, or in the presence of one of fever $\left(>38^{\circ} \mathrm{C}\right)$, chills, or 
hypotension and any of the following: a common skin contaminant isolated from two blood cultures that were drawn on separate occasions; a common skin contaminant isolated from the blood culture of a patient with an intravascular access device, and the physician instituted appropriate antimicrobial therapy; or a positive antigen blood test [27].

Gastrointestinal bleeding was defined as the presence of hematemesis, melena, bright red blood per rectum, or a coffee grounds-like substance that was aspirated from the feeding tube. Patients with hypoglycemia were defined as those who developed at least one episode of hypoglycemia. A moderate hypoglycemic event was defined as a blood glucose concentrations $\leq 60$ and $>40$ $\mathrm{mg} / \mathrm{dl}$. A severe hypoglycemic event was defined as blood glucose concentration $\leq 40 \mathrm{mg} / \mathrm{dl}$.

The 24-hour nitrogen balance was calculated using the following formula [28]:

$$
\text { Nitrogen balance }=(\text { protein intake/6.25 })-(U U N+4)
$$

The difference in daily insulin dose between the two groups was the total mean insulin dose of the MIT group minus the total mean insulin dose of the CIT group on the same day.

\section{Outcomes}

Primary outcomes included 24-hour UUN levels, nitrogen balance, serum albumin concentrations, and prealbumin concentrations. Secondary outcomes included ICU days, ventilator days, hospital days, acute renal injury, bloodstream infection, blood transfusions, gastrointestinal bleeding, moderate hypoglycemia, severe hypoglycemia, and hospital mortality rate.

\section{Statistical analysis}

All data were analyzed by SPSS version 12.0 (SPSS, Inc., Chicago, IL, USA). Data are presented as the mean \pm standard deviation, median (interquartile range), or number (percentage). All data were analyzed according to the intention-to-treat principle. To detect differences of nitrogen balance using a two-sided 5\% significance level and a power of $85 \%$ when the difference and standard deviation were equal to 0.80 and 1.97 , a sample size of 55 patients per group was necessary. This value was based on previous studies involving nitrogen balance and different doses of insulin treatment in a burn ICU [21]. Primary outcomes, such as 24-hour UUN levels, nitrogen balance, serum albumin concentrations, and prealbumin concentrations were analyzed with a generalized linear model for repeated measures using dummy variables. Student's $t$ test was used to compare continuous variables with normally distributed data. Wilcoxon's rank-sum tests were used to compare continuous variables with non-normally distributed data. Chi-square tests were used to compare dichotomous variables. All $P$ values were two-tailed. $P<0.05$ was considered significant.

\section{Results}

\section{Patient characteristics}

All participants were recruited from April 2006 to December 2006. This trial ended when it reach the sample size goal. Of the 112 patients randomized to the study, 55 patients received MIT and 57 patients received CIT. All patients were available for the intention-to-treat analysis (Figure 1). Table 1 shows the patient baseline characteristics of all the patients enrolled in the study. Demographic data at the time of randomization showed no significant differences in any of the parameters. Figure 2 shows serum creatinine, creatinine clearance, and urine output during the study period between the two groups; there were no significant differences. The two groups shared similar background characteristics.

\section{Nutrition and blood glucose control}

Actual daily protein (grams per day and per kilogram of body weight) and caloric (calories per day and per kilogram of body weight) intake, blood glucose concentrations, and insulin dose (per hour corrected for caloric intake) are shown in Figure 3. Daily protein and caloric intake progressively increased until day 5 , but then fluctuated after day 5 in both groups. The two treatment groups had similar protein and caloric intakes. The mean blood glucose concentration was $125.3 \pm 2.4 \mathrm{mg} /$ $\mathrm{dl}$ in the patients of the MIT group and $199.9 \pm 4.0 \mathrm{mg} /$ $\mathrm{dl}(P<0.01)$ in the patients of the CIT group. The median daily insulin dose was 82 (69 to 111$)$ units/day in the patients of the MIT group and 37 (26 to 43) units/ day $(P<0.01)$ in the patients of the CIT group (Table 2 ). To maintain the low blood glucose concentrations, patients in the MIT group were administered a significantly higher insulin dose than patients in the CIT group. The insulin requirement per calorie decreased each day in both groups (Figure 3). The difference in mean daily insulin doses between the two groups ranged from $58 \mathrm{IU} /$ day on day 1 to $43 \mathrm{IU} /$ day on day 14 . The difference in insulin requirements per day between the two groups decreased each day (Figure 4).

\section{Primary outcomes}

Both groups showed a trend of decreasing levels of excreted urinary nitrogen, better nitrogen balance, and increasing serum albumin and prealbumin concentrations during their hospital courses. A generalized linear model for repeated measurements using dummy variables revealed that there were significantly lower 24-hour urine nitrogen excretion $(P=0.027)$ (Figure 5$)$ and higher 
Table 1 Demographic data for all patients

\begin{tabular}{|c|c|c|c|}
\hline Characteristic & MIT group $(n=55)$ & CIT group $(n=57)$ & $P$ value \\
\hline \multicolumn{4}{|l|}{ Primary ICU admitting diagnosis } \\
\hline Sepsis & 25 & 26 & \\
\hline Respiratory & 11 & 12 & \\
\hline Neurologic & 9 & 7 & \\
\hline Cardiovascular & 3 & 5 & \\
\hline Gastrointestinal or liver & 2 & 3 & \\
\hline Hematologic or oncologic & 3 & 1 & \\
\hline Renal & 1 & 2 & \\
\hline Metabolic & 1 & 1 & \\
\hline Age & $68.1 \pm 16.3$ & $70.4 \pm 12.1$ & 0.40 \\
\hline Body weight (kg) & $61.4 \pm 9.6$ & $62.5 \pm 9.8$ & 0.57 \\
\hline Gender (female/male) & 16/39 (41\%) & 16/41 (39\%) & 0.90 \\
\hline Body mass index $\left(\mathrm{kg} / \mathrm{m}^{2}\right)$ & $23.6 \pm 3.0$ & $23.9 \pm 3.8$ & 0.72 \\
\hline History of diabetes & 19/55 (34.5\%) & $22 / 57(38.6 \%)$ & 0.67 \\
\hline Previous corticosteroid treatment & $14 / 55(25.4 \%)$ & 16/57 (28.1\%) & 0.77 \\
\hline Use of inotropes & $15 / 55(27.3)$ & $12 / 57(21.1)$ & 0.44 \\
\hline APACHE II score & 20 (17 to 25$)$ & 21 (16.5 to 26.5$)$ & 0.94 \\
\hline Patients with total parenteral nutrition & $2 / 55(3.6 \%)$ & $2 / 57(3.5 \%)$ & 0.97 \\
\hline \multicolumn{4}{|l|}{ Intake of nutrients } \\
\hline Carbohydrate (\%) & $54.3 \pm 0.2$ & $54.4 \pm 0.2$ & 0.84 \\
\hline Protein (\%) & $16.4 \pm 0.1$ & $16.4 \pm 0.2$ & 0.50 \\
\hline Fat (\%) & $29.3 \pm 0.2$ & $29.2 \pm 0.8$ & 0.55 \\
\hline \multicolumn{4}{|l|}{ At randomization } \\
\hline Blood glucose $(\mathrm{mg} / \mathrm{dl})$ & $229.2 \pm 39.3$ & $231.1 \pm 52.1$ & 0.93 \\
\hline Serum hemoglobin (g/dl) & $10.9 \pm 2.2$ & $10.8 \pm 2.3$ & 0.80 \\
\hline Serum ALT (U/I) & $59.1 \pm 79.3$ & $63.8 \pm 83.0$ & 0.76 \\
\hline Serum total bilirubin (mg/dl) & $1.1 \pm 0.4$ & $1.2 \pm 0.4$ & 0.88 \\
\hline UUN (g/BSA/24 hours) & $7.0 \pm 3.7$ & $6.7 \pm 3.8$ & 0.78 \\
\hline Nitrogen balance (g/BSA/day) & $-4.8 \pm 5.9$ & $-4.7 \pm 4.5$ & 0.93 \\
\hline Serum albumin (mg/dl) & $1,949.9 \pm 376.0$ & $1,955.4 \pm 506.5$ & 0.95 \\
\hline Serum prealbumin (mg/dl) & $11.3 \pm 5.2$ & $11.2 \pm 4.5$ & 0.87 \\
\hline
\end{tabular}

Data presented as $n$, mean \pm standard deviation, or median (interquartile range). ALT, alanine aminotransferase; APACHE, Acute Physiology and Chronic Health Evaluation; BSA, body surface area; CIT, conventional insulin therapy; MIT, moderate insulin therapy; UUN, urinary urea nitrogen.

serum albumin $(P=0.047)$ and prealbumin $(P=0.001)$ concentrations (Figure 6) during the study period in the MIT group. The MIT group exhibited a higher nitrogen balance than the CIT group; however, this difference was not statistically significant $(P=0.070)$. Differences in 24hour urine nitrogen excretion, nitrogen balance, serum albumin concentrations, and prealbumin concentrations between the two groups were most significant on day 3 when all factors showed significant differences $(P<0.05)$. These differences decreased after day 3.

\section{Secondary outcomes}

There were no statistically significant differences in ICU days, ventilator days, hospital days, rate of acute renal injury, bloodstream infection, red-blood-cell transfusion, and gastrointestinal bleeding in the two groups (Table 2).
Moderate hypoglycemia (blood glucose levels $\leq 60$ $\mathrm{mg} / \mathrm{dl}$ and $>40 \mathrm{mg} / \mathrm{dl}$ ) occurred more often in the MIT group than in the CIT group, but this difference was not statistically significant $(18.2 \%$ vs. $10.5 \%, P=0.10$; 2.4 episodes vs. 1.5 episodes per 100 treatment days, $P$ $=0.18$ ) (Table 2). The CIT group also exhibited a lower rate of severe hypoglycemia (blood glucose levels $\leq 40$ $\mathrm{mg} / \mathrm{dl})$, but the difference was not significant (3.6\% vs. $1.8 \%, P=0.53 ; 0.3$ episodes vs. 0.2 episodes per 100 treatment days, $P=0.44$ ). No hemodynamic deterioration, convulsions, or neurological sequelae were noted in association with any hypoglycemic event in either group.

Patients with MIT had a trend for lower hospital mortality rate than that of patients with CIT, but they did not reach a statistically significant difference. 

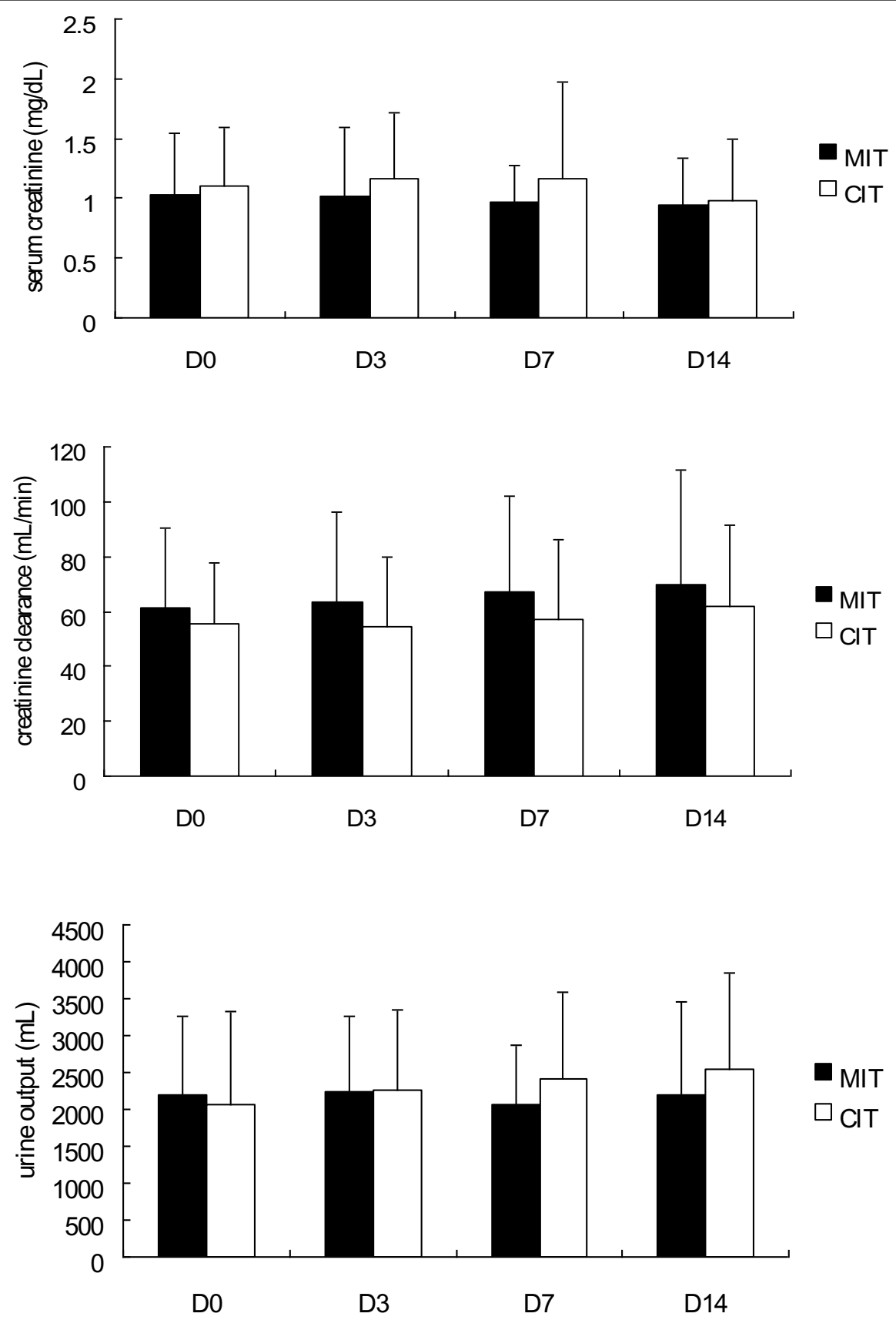

Figure 2 Serum creatinine, creatinine clearance and 24-hour urine output on days $\mathbf{0 , 3}$, 7, and $\mathbf{1 4}$. Top, serum creatinine; middle, creatinine clearance; bottom, 24-hour urine output. Filled bars, patients receiving moderate insulin therapy (MIT group); open bars, patients receiving conventional insulin therapy (CIT group).

\section{Discussion}

The results of this study showed that MIT could significantly improve nitrogen balance in the early stages of critical illness. Patients treated with MIT had significantly lower urinary nitrogen excretion and higher serum albumin and prealbumin concentrations than patients treated with CIT.
In the present study, both groups showed a negative nitrogen balance during the study period. Although the nitrogen balance was negative, both groups showed improvement during the study period. Protein is rapidly broken down in critically ill patients who are subjected to high stress [18]. Hypermetabolism in patients under stress is associated with an increased negative nitrogen balance, 

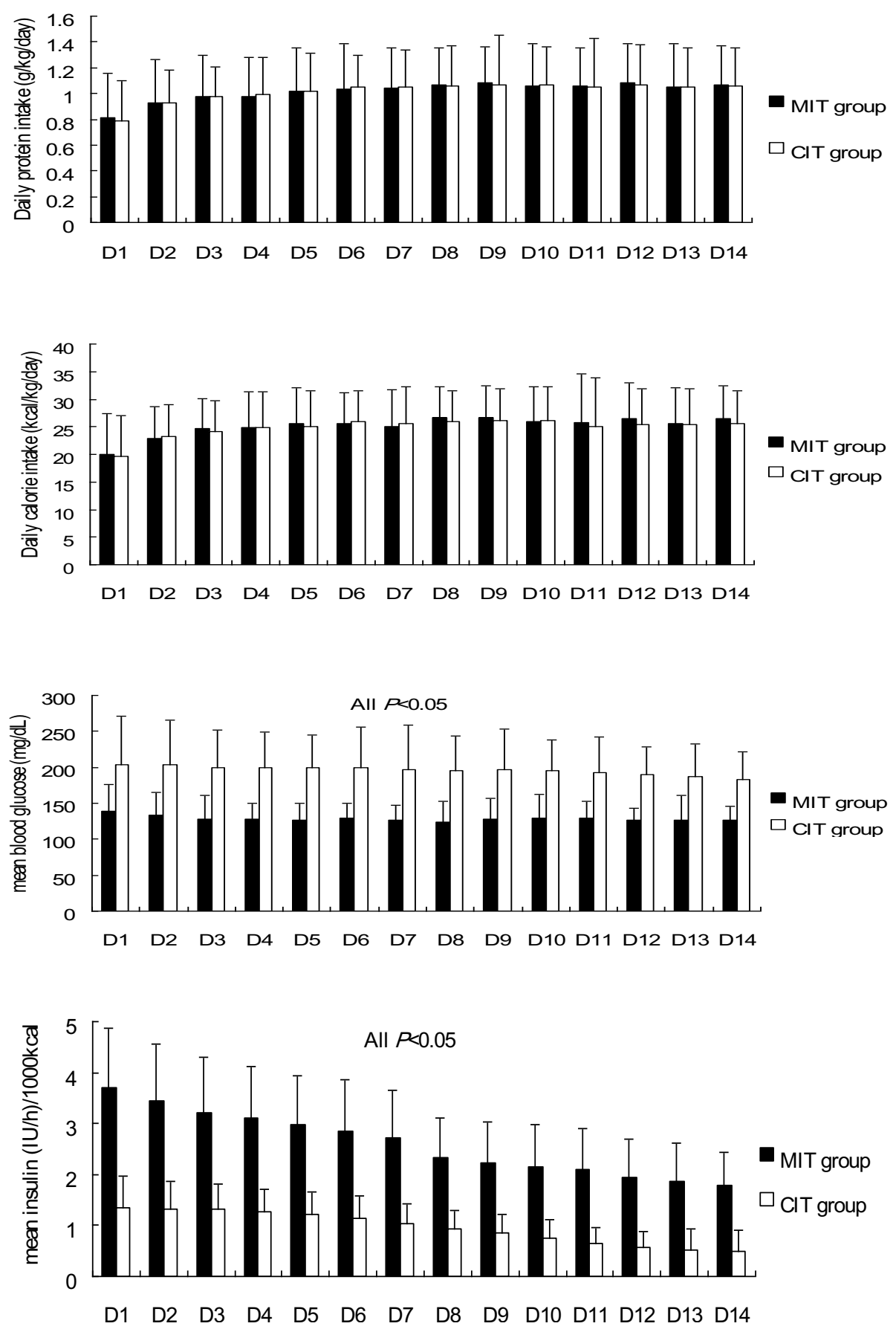

Figure 3 Daily protein, calories intake, mean blood glucose levels and insulin dose. Daily protein intake (top), daily caloric intake (second from top), mean blood glucose levels (second from bottom), and insulin dose (bottom) during the 2-week study period in the medical ICU. Filled bars, moderate insulin therapy (MIT) group; open bars, conventional insulin therapy (CIT) group.

and a positive nitrogen balance is difficult to attain in hypermetabolic patients [29]. Equilibrium between energy intake and energy expenditure, early feeding, and a highprotein diet may improve nitrogen balance [30-32]. In this study, nitrogen balance was improved using moderate glucose control. This improvement may have arisen from higher dose insulin administered to the MIT group during the hospital course. Higher infused doses of insulin can result in a marked reduction in UUN excretion and a better nitrogen balance [21].

Differences in nitrogen balance between the two treatment groups were significant in the early stages of 
Table 2 Clinical outcomes

\begin{tabular}{llll}
\hline Outcome variable & MIT group $(\boldsymbol{n}=\mathbf{5 5})$ & CIT group $(\boldsymbol{n}=\mathbf{5 7})$ & $\boldsymbol{P}$ value \\
\hline Mean blood glucose (mg/dl) & $125.3 \pm 17.8$ & $199.9 \pm 30.2$ & $<0.01$ \\
Daily dose of insulin (unit/day) & $82(69$ to 111$)$ & $37(26$ to 44$)$ & $<0.01$ \\
ICU days & $14(9$ to 19$)$ & $15(11$ to 26$)$ & 0.26 \\
Ventilator days & $20(11$ to 30$)$ & $23(11$ to 43.5$)$ & 0.19 \\
Hospital days & $27(15$ to 36$)$ & $32(18.5$ to 51.3$)$ & 0.052 \\
Acute renal injury & $3 / 55(5.5 \%)$ & $7 / 57(12.3 \%)$ & 0.10 \\
Bloodstream infection & $1 / 55(1.8 \%)$ & $3 / 57(5.3 \%)$ & 0.33 \\
Red-blood-cell blood transfusion & $12 / 55(21.8 \%)$ & $15 / 57(26.3 \%)$ & 0.74 \\
Gastrointestinal bleeding & $7 / 55(12.7 \%)$ & $7 / 57(12.3 \%)$ & 0.83 \\
Number of mild hypoglycemia & $10 / 55(18.2 \%)$ & $6 / 57(10.5 \%)$ & 0.37 \\
Rate of moderate hypoglycemia per 100 treatment days & 2.4 & 1.5 & 0.18 \\
Number of severe hypoglycemia & $2 / 55(3.6 \%)$ & $1 / 57(1.8 \%)$ & 0.53 \\
Rate of severe hypoglycemia per 100 treatment days & 0.3 & 0.2 & 0.44 \\
Hospital mortality rate & $18 / 55(32.7 \%)$ & $28 / 57(49.1 \%)$ & 0.08 \\
\hline
\end{tabular}

Data presented as $n$, mean \pm standard deviation, or median (interquartile range). CIT, conventional insulin therapy; MIT, moderate insulin therapy.

critical illness, but decreased over time. This observation may be related to the insulin dose. Differences in insulin dose between the two groups were more significant in the early stages than in the late stages.

The effect of insulin on protein metabolism appears primarily to be due to inhibition of proteolysis [33-35], although increased protein synthesis has been reported [36]. In healthy subjects, insulin inhibits proteolysis in a dose-dependent manner [37]. Insulin binding to its receptors activates the insulin receptor substrate pathway, leading to activation of protein kinase; protein kinase B modulates enzyme activities that affect nitric oxide generation and control protein metabolism [38].

Insulin also has an anabolic effect that is beneficial to critically ill patients; it may increase levels of insulin-like growth factor (IGF)-1, a mediator of anabolic growth hormone action, and decrease hepatic synthesis of IGF1 binding protein, leading to the increased bioavailability of IGF-1 [39]. In a study involving rats, IGF-1 administration significantly improved nitrogen balance [40].

Critical illness is characterized by hypermetabolism and catabolism, leading to peripheral protein waste $[41,42]$. Proinflammatory mediators enhance catabolism and hypermetabolism by inhibition of the growth hormoneIGF-I-insulin axis [43-45]. Insulin improves hypermetabolism by affecting proinflammatory cytokine production and hepatic signal transcription factor expression [46]; it attenuates the inflammatory response by decreasing the proinflammatory cascade and increasing the anti-inflammatory cascade. By decreasing proinflammatory mediators, liver constitutive proteins such as albumin and

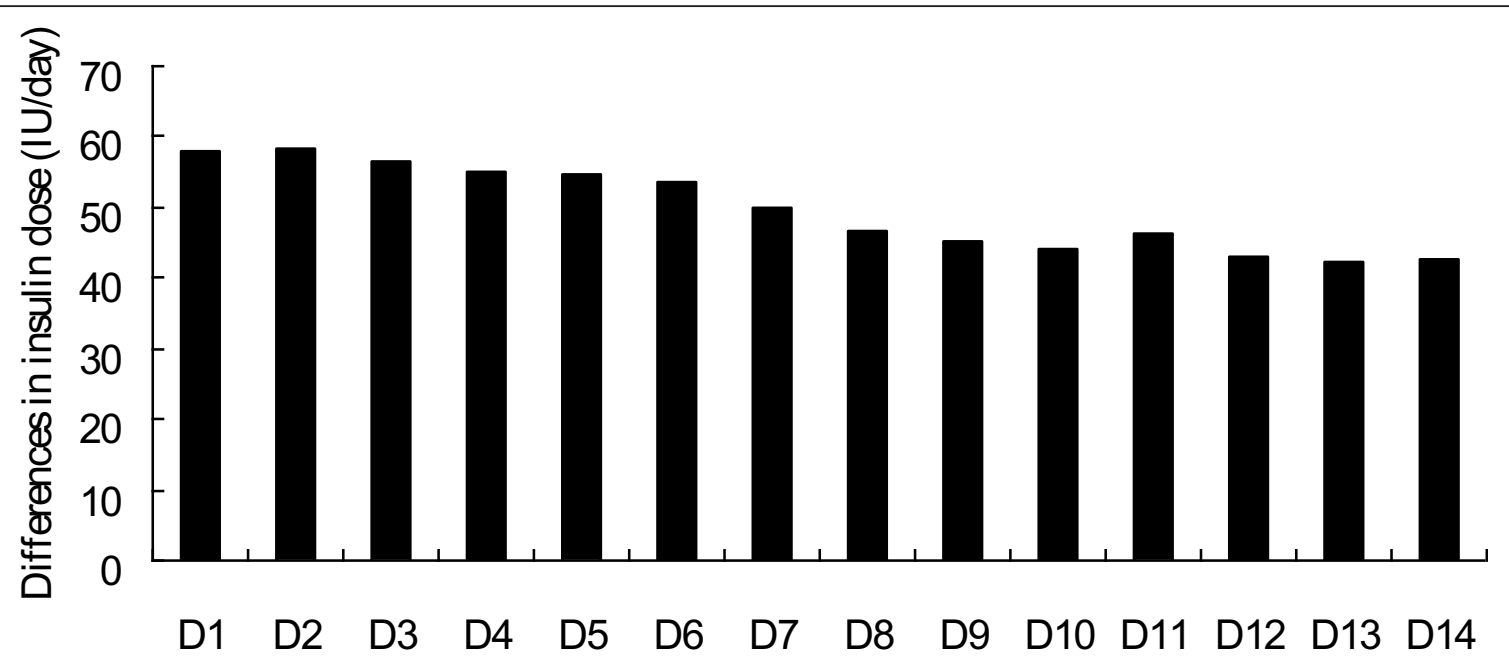

Figure 4 Differences in mean daily insulin doses between moderate and conventional insulin therapy. Differences in mean daily insulin doses between the moderate insulin therapy group and the conventional insulin therapy group. 

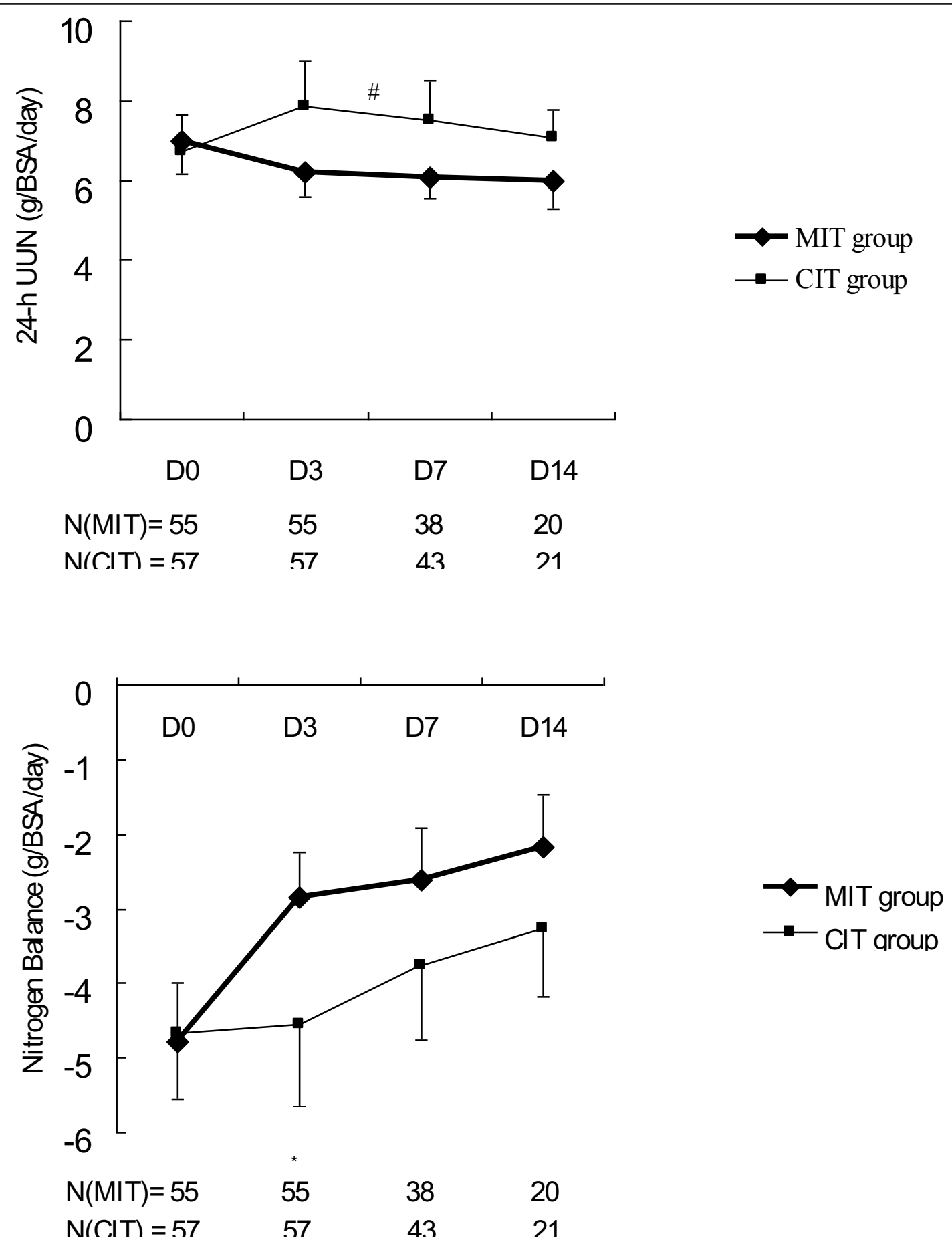

Figure 5 Twenty-four-hour urinary urea nitrogen and nitrogen balance in patients receiving moderate or conventional insulin therapy. Top, 24-hour urinary urea nitrogen (UUN); bottom, nitrogen balance. Data represent the mean \pm standard deviation. A generalized linear model of repeated measurements showed statistically significant differences between the two groups: ${ }^{\#} P=0.027$ for entire study period, ${ }^{*} P<0.05$ for day 3. BSA, body surface area; CIT, conventional insulin therapy; MIT, moderate insulin therapy.

prealbumin are increased [47]. Inflammation reduces the albumin concentration by decreasing its rate of synthesis and increasing transfer of albumin out of the vascular compartment [48].
Although our data and previous studies have shown that insulin benefits protein metabolism, the extent to which the benefit is derived from the correction of hyperglycemia as opposed to the direct effects of insulin remains unclear 


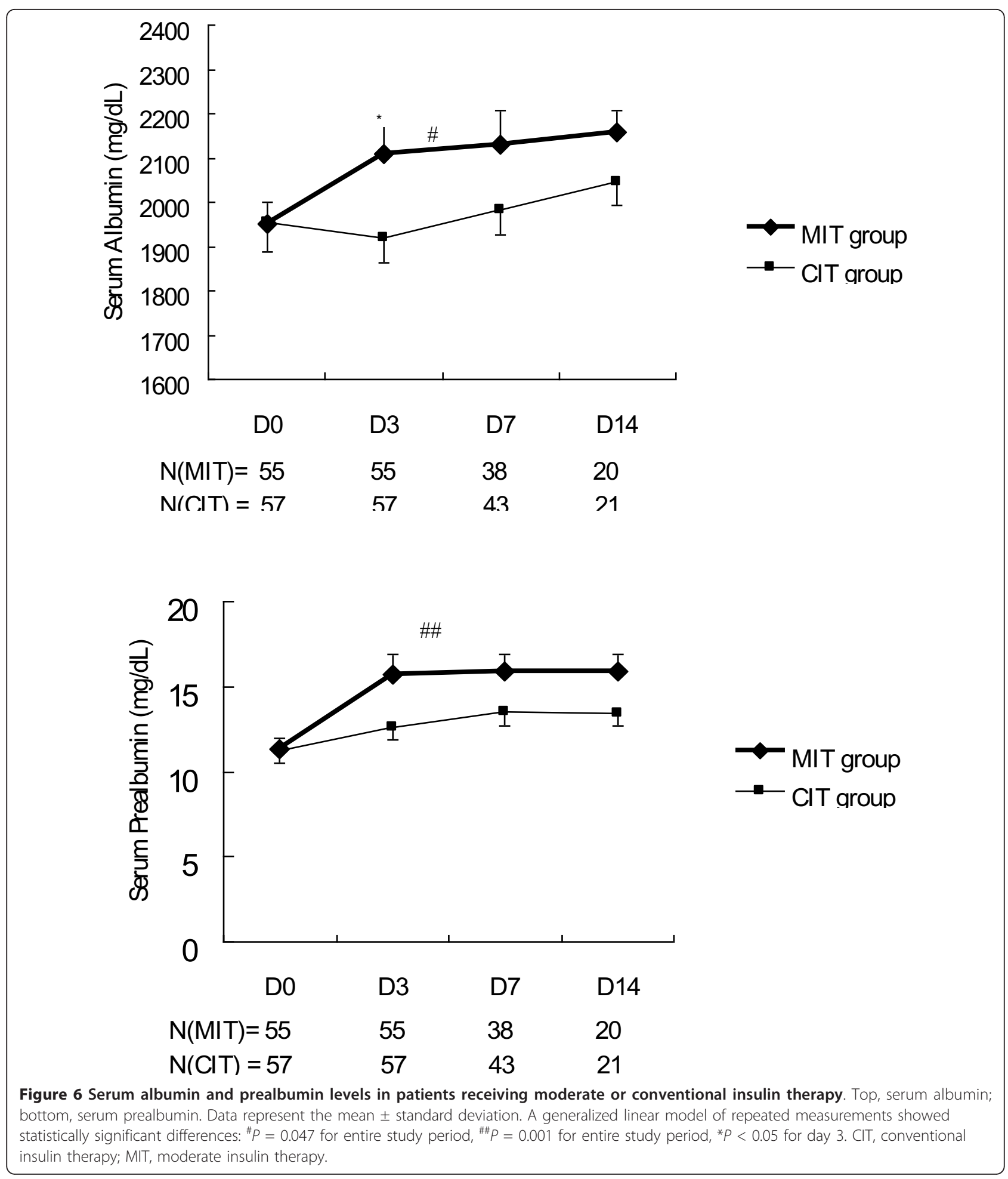

[49]. Van den Berghe and colleagues revealed that the lowering of blood glucose levels rather than the amount of infused insulin is related to the effects of insulin therapy on morbidity [7]. Acute hyperglycemia enhances proteolysis in the entire body during hyperinsulinemia in normal men [50]. Additionally, Whyte and colleagues demonstrated that the administration of insulin which resulted in supraphysiological concentrations did not attenuate protein breakdown and had no effect on the net protein balance in critically ill patients [51]. 
For patients receiving total parenteral nutrition, glucose and lipid ratios influence the nitrogen balance. A previous study showed that total parenteral nutrition at a glucose/lipid ratio of 50/50 induced a significantly higher nitrogen balance than an 80/20 ratio with an isocaloric isonitrogenous parenteral nutrition formula [52]. In our study, few patients received total parenteral nutrition and they had a similar glucose/lipid ratio; thus, the glucose/lipid ratio is not a confounding factor for maintaining nitrogen balance.

A meta-analysis study showed that intensive insulin therapy has no advantage in reducing the mortality rate, but significantly increases the risk of hypoglycemia [53]. Our study demonstrated that most patients with hypoglycemia have a moderate form; severe hypoglycemia was rarely observed. Target glucose levels in our study were 120 to $140 \mathrm{mg} / \mathrm{dl}$, which was higher than those in intensive insulin therapy studies that had a target below $110 \mathrm{mg} / \mathrm{dl}[5,8]$. The rate of severe hypoglycemia in the intensive insulin therapy ranged from 5.1 to $28.6 \%$ [5,9-13]. The rate of severe hypoglycemia was lower in our study (3.6\%) compared with previous studies that adopted intensive glucose control. Moderate glucose control was safer than intensive glucose control regarding severe hypoglycemia.

There are some limitations to our study. First, this was a single-center study limited to medical ICU patients without chronic renal loss. These results do not represent all critically ill patients. Second, our study was not double-blind because safe insulin titration required the monitoring of blood glucose levels. Doctors and nurses should be aware of target glucose control levels. All patients did follow the same protocol, however, except for those following the glucose control protocol. Third, the study group was only moderately sized. Some parameters, such as clinical outcomes, did not show a significant difference due to the small sample size. Further studies are needed to examine larger sample sizes.

\section{Conclusion}

Patients treated with MIT had significantly lower urinary nitrogen excretion and higher serum albumin and prealbumin concentrations compared with patients treated with CIT. Moderate glucose control can result in a less negative nitrogen balance in medical ICU patients. This difference was more significant in the early stages compared with the late stages of critical illness.

\section{Key messages}

- Patients treated with MIT had significantly lower urinary nitrogen excretion and higher serum albumin and prealbumin concentrations than patients treated with CIT.
- Moderate glucose control can result in a less negative nitrogen balance; this may be related to insulin. - The difference of nitrogen balance between MIT and CIT was more significant in the early stages compared with the late stages of critical illness in medical ICU patients.

\section{Additional material}

Additional file 1: Appendix 1 showing the insulin protocol.

\section{Abbreviations}

CIT: conventional insulin therapy; IGF: insulin-like growth factor; IL: interleukin; MIT: moderate insulin therapy; TNF: tumor necrosis factor; UUN: urinary urea nitrogen.

\section{Acknowledgements}

The authors would like to thank the medical staff (physicians, nurses and dietitians) in the ICUs of Kaohsiung Veterans General Hospital for their assistance in this study. Financial support was received from Kaohsiung Veterans General Hospital, No. VGHKS 95-070 (C-WH received an academic research fund from Kaohsiung Veterans General Hospital).

\section{Author details}

${ }^{1}$ Intensive Care Unit, Department of Medicine, Kaohsiung Veterans General Hospital, 386 Ta-Chung $1^{\text {st }}$ Road, Kaohsiung City 813, Taiwan. ${ }^{2}$ Medicine Department, School of Medicine, National Yang-Ming University, 155 Sec. 2 Linong street, Taipei City 112, Taiwan. ${ }^{3}$ Department of Physical Medicine and Rehabilitation, Kaohsiung Veterans General Hospital, 386 Ta-Chung $1^{\text {st }}$ Road, Kaohsiung City 813, Taiwan. ${ }^{4}$ Department of Food and Nutrition, Taipei Veterans General Hospital, 201 Sec. 2 Shipai Road, Beitou District, Taipei City 112, Taiwan. ${ }^{5}$ Institute of Statistics, National University of Kaohsiung, 700 Kaohsiung University Road, Nanzih District, Kaohsiung City 811, Taiwan.

\section{Authors' contributions}

C-WH was the main contributor to the design of the study, interpretation of the data, and drafting of the manuscript. S-FS contributed to the acquisition and analysis of the data. S-LL contributed to design of the study and revision of the manuscript. K-FW contributed to statistical analysis of the data. $\mathrm{H}-\mathrm{HH}$ contributed to the execution of the study. All authors read and approved the final manuscript.

\section{Competing interests}

The authors declare that they have no competing interests.

Received: 9 January 2012 Revised: 15 March 2012

Accepted: 5 April 2012 Published: 5 April 2012

\section{References}

1. Levetan CS, Passaro M, Jablonski K, Kass M, Ratner RE: Unrecognized diabetes among hospitalized patients. Diabetes Care 1998, 21:246-249.

2. Umpierrez GE, Isaacs SD, Bazargan N, You X, Thaler LM, Kitabchi AE: Hyperglycemia: an independent marker of in-hospital mortality in patients with undiagnosed diabetes. J Clin Endocrinol Metab 2002, 87:978-982.

3. Mizock BA: Alterations in fuel metabolism in critical illness: hyperglycaemia. Best Pract Res Clin Endocrinol Metab 2001, 15:533-551.

4. Robinson $L E$, van Soeren $M H$ : Insulin resistance and hyperglycemia in critical illness: role of insulin in glycemic control. AACN Clin Issues 2004, 15:45-62.

5. Van den Berghe G, Wouters P, Weekers F, Verwaest C, Bruyninckx F, Schetz M, Vlasselaers D, Ferdinande P, Lauwers P, Bouillon R: Intensive insulin therapy in the critically ill patients. N Engl J Med 2001, 345:1359-1367. 
6. McCowen KC, Malhotra A, Bistrian BR: Stress-induced hyperglycemia. Crit Care Clin 2001, 17:107-124

7. Van den Berghe G, Wouters PJ, Bouillon R, Weekers F, Verwaest C, Schetz M, Vlasselaers D, Ferdinande P, Lauwers P: Outcome benefit of intensive insulin therapy in the critically ill: insulin dose vs. glycemic control. Crit Care Med 2003, 31:359-366.

8. Van den Berghe G, Wilmer A, Hermans G, Meersseman W, Wouters PJ, Milants I, Van Wijngaerden E, Bobbaers H, Bouillon R: Intensive insulin therapy in the medical ICU. N Engl J Med 2006, 354:449-461.

9. Brunkhorst FM, Engel C, Bloos F, Meier-Hellmann A, Ragaller M, Weiler N, Moerer O, Gruendling M, Oppert M, Grond S, Olthoff D, Jaschinski U, John S, Rossaint R, Welte T, Schaefer M, Kern P, Kuhnt E, Kiehntopf M, Hartog C, Natanson C, Loeffler M, Reinhart K, German Competence Network Sepsis (SepNet): Intensive insulin therapy and pentastarch resuscitation in severe sepsis. N Engl J Med 2008, 358:125-139.

10. De La Rosa Gdel C, Donado JH, Restrepo AH, Quintero AM, González LG, Saldarriaga NE, Bedoya M, Toro JM, Velásquez JB, Valencia JC, Arango CM, Aleman PH, Vasquez EM, Chavarriaga JC, Yepes A, Pulido W, Cadavid CA, Grupo de Investigacion en Cuidado intensivo GICI-HPTU: Strict glycaemic control in patients hospitalised in a mixed medical and surgical intensive care unit: a randomised clinical trial. Crit Care 2008, 12:R120.

11. Arabi YM, Dabbagh OC, Tamim HM, Al-Shimemeri AA, Memish ZA, Haddad SH, Syed SJ, Giridhar HR, Rishu AH, Al-Daker MO, Kahoul SH, Britts RJ, Sakkijha MH: Intensive versus conventional insulin therapy: a randomized controlled trial in medical and surgical critically ill patients. Crit Care Med 2008, 36:3190-3197.

12. Preiser JC, Devos P, Ruiz-Santana S, Mélot C, Annane D, Groeneveld J, lapichino G, Leverve X, Nitenberg G, Singer P, Wernerman J, Joannidis M, Stecher A, Chioléro R: A prospective randomised multi-centre controlled trial on tight glucose control by intensive insulin therapy in adult intensive care units: the Glucontrol study. Intensive Care Med 2009, 35:1738-1748

13. Finfer $S$, Chittock DR, Su SY, Blair D, Foster D, Dhingra V, Bellomo R, Cook D, Dodek P, Henderson WR, Hébert PC, Heritier S, Heyland DK, McArthur C, McDonald E, Mitchell I, Myburgh JA, Norton R, Potter J, Robinson BG, Ronco JJ: Intensive versus conventional glucose control in critically ill patients. N Engl J Med 2009, 360:1283-1297.

14. Bhamidipati CM, LaPar DJ, Stukenborg GJ, Morrison CC, Kern JA, Kron IL, Ailawadi G: Superiority of moderate control of hyperglycemia to tight control in patients undergoing coronary artery bypass grafting. $J$ Thorac Cardiovasc Surg 2011, 141:543-551.

15. Jeschke MG, Kraft R, Emdad F, Kulp GA, Williams FN, Herndon DN: Glucose control in severely thermally injured pediatric patients: what glucose range should be the target? Ann Surg 2010, 252:521-528.

16. Hasselgren $\mathrm{PO}$, James $\mathrm{JH}$, Benson DW, Hall-Angerås $\mathrm{M}$, Angerås $\mathrm{U}$, Hiyama DT, Li S, Fischer JE: Total and myofibrillar protein breakdown in different types of rat skeletal muscle: effects of sepsis and regulation by insulin. Metabolism 1989, 38:634-640.

17. Vary TC, Kimball SR: Sepsis-induced changes in protein synthesis: differential effects on fast- and slow-twitch muscles. Am J Physiol 1992, 262:C1513-C1519.

18. Btaiche IF, Chan LN, Pleva M, Kraft MD: Critical illness, gastrointestinal complications, and medication therapy during enteral feeding in critically ill adult patients. Nutr Clin Pract 2010, 25:32-49.

19. Almdal TP, Vilstrup H: Strict insulin therapy normalises organ nitrogen contents and the capacity of urea nitrogen synthesis in experimental diabetes in rats. Diabetologia 1988, 31:114-118.

20. Woolfson AM, Heatley RV, Allison SP: Insulin to inhibit protein catabolism after injury. N Engl I Med 1979, 300:14-17.

21. Shiozaki T, Tasaki O, Ohnishi M, Nishimura T, Hiraide A, Shimazu T, Yoshioka T, Sugimoto H: Paradoxical positive nitrogen balance in burn patients receiving high-dose administration of insulin for nutritional care. Surgery 1997, 122:527-533.

22. Bellomo R, Ronco C, Kellum JA, Mehta RL, Palevsky P, Acute Dialysis Quality Initiative Workgroup: Acute renal failure - definition, outcome measures, animal models, fluid therapy and information technology needs: the Second International Consensus Conference of the Acute Dialysis Quality Initiative (ADQI) group. Crit Care 2004, 8:R204-R212.

23. Heyland DK, Dhaliwal R, Drover JW, Gramlich L, Dodek P, Canadian Critical Care Clinical Practice Guidelines Committee: Canadian clinical practice guidelines for nutrition support in mechanically ventilated, critically ill adults patients. JPEN J Parenter Enteral Nutr 2003, 27:355-373.

24. Dellinger RP, Carlet JM, Masur H, Gerlach H, Calandra T, Cohen J, GeaBanacloche J, Keh D, Marshall JC, Parker MM, Ramsay G, Zimmerman JL, Vincent JL, Levy MM, Surviving Sepsis Campaign Management Guideline Committee: Surviving Sepsis Campaign guidelines for management of severe sepsis and septic shock. Crit Care Med 2004, 32:858-873.

25. Levy MM, Fink MP, Marshall JC, Abraham E, Angus D, Cook D, Cohen J, Opal SM, Vincent JL, Ramsay G, International Sepsis Definitions Conference: 2001 SCCM/ESICM/ACCP/ATS/SIS International Sepsis Definitions Conference. Intensive Care Med 2003, 29:530-538.

26. Cockcroft DW, Gault MH: Prediction of creatinine clearance from serum creatinine. Nephron 1976, 16:31-41.

27. Garner JS, Jarvis WR, Emori TG, Horan TC, Hughes JM: CDC definitions for nosocomial infections, 1988. Am J Infect Control 1988, 16:128-140.

28. Blackburn GL, Bistrian BR, Maini BS, Schlamm HT, Smith MF: Nutritional and metabolic assessment of the hospitalized patient. JPEN J Parenter Enteral Nutr 1977, 1:11-22.

29. Pingleton SK: Nutrition in chronic critical illness. Clin Chest Med 2001, 22:149-163.

30. Japur CC, Monteiro JP, Marchini JS, Garcia RW, Basile-Filho A: Can an adequate energy intake be able to reverse the negative nitrogen balance in mechanically ventilated critically ill patients? J Crit Care 2010, 25:445-450.

31. Jivnani $S$, lyer $S$, Umakumar K, Gore MA: Impact of enteral nutrition on nitrogen balance in patients of trauma. J Emerg Trauma Shock 2010, 3:109-114.

32. Bellomo R, Seacombe J, Daskalakis M, Farmer M, Wright C, Parkin G, Boyce N: A prospective comparative study of moderate versus high protein intake for critically ill patients with acute renal failure. Ren Fail 1997, 19:111-120.

33. Castellino P, Luzi L, Simonson DC, Haymond M, DeFronzo RA: Effect of insulin and plasma amino acid concentrations on leucine metabolism in man. Role of substrate availability on estimates of whole body protein synthesis. J Clin Invest 1987, 80:1784-1793.

34. Fukagawa NK, Minaker KL, Rowe JW, Goodman MN, Matthews DE, Bier DM, Young VR: Insulin-mediated reduction of whole body protein breakdown. Dose-response effects on leucine metabolism in postabsorptive men. J Clin Invest 1985, 76:2306-2311.

35. Nair KS, Ford GC, Ekberg K, Fernqvist-Forbes E, Wahren J: Protein dynamics in whole body and in splanchnic and leg tissues in type I diabetic patients. J Clin Invest 1995, 95:2926-2937.

36. Biolo G, Declan Fleming RY, Wolfe RR: Physiologic hyperinsulinemia stimulates protein synthesis and enhances transport of selected amino acids in human skeletal muscle. J Clin Invest 1995, 95:811-819.

37. Tessari P, Inchiostro S, Biolo G, Trevisan R, Fantin G, Marescotti MC, lori E, Tiengo A, Crepaldi G: Differential effects of hyperinsulinemia and hyperaminoacidemia on leucine-carbon metabolism in vivo. Evidence for distinct mechanisms in regulation of net amino acid deposition. J Clin Invest 1987, 79:1062-1069.

38. Van den Berghe G: How dose blood glucose control with insulin save lives in intensive care? J Clin Invest 2004, 114:1187-1195.

39. Brismar K, Fernqvist-Forbes E, Wahren J, Hall K: Effect of insulin on the hepatic production of insulin-like growth factor-binding protein-1 (IGFBP-1), IGFBP-3, and IGF-I in insulin-dependent diabetes. J Clin Endocrinol Metab 1994, 79:872-878.

40. Núñez M, Urdaneta E, Santidrián S: Effect of insulin-like growth factor-I on nitrogen balance and intestinal galactose transport in rats with moderate liver cirrhosis. Br J Nutr 2003, 90:929-937.

41. Rennie MJ: Muscle protein turnover and the wasting due to injury and disease. Br Med Bull 1985, 41:257-264.

42. Wilmore DW: Catabolic illness. Strategies for enhancing recovery. N Engl J Med 1991, 325:695-702

43. Van den Berghe $G$, de Zegher F, Veldhuis JD, Wouters P, Awouters M, Verbruggen $W$, Schetz $M$, Verwaest $C$, Lauwers $P$, Bouillon $R$, Bowers $C Y$ : The somatotropic axis in critical illness: effect of continuous growth hormone (GH)-releasing hormone and GH-relaesing peptide-2 infusion. $J$ Clin Endocrinol Metab 1997, 82:590-599.

44. Frost RA, Lang CH, Gelato MC: Transient exposure of human myoblasts to tumor necrosis factor-alpha inhibits serum and insulin-like growth factors-I stimulated protein synthesis. Endocrinology 1997, 138:4153-4159. 
45. Timmins AC, Cotterill AM, Hughes SC, Holly JM, Ross RJ, Blum W, Hinds CJ: Critical illness is associated with low circulating concentrations of insulin-like growth factors-I and -II, alterations in insulin-like growth hormone factors binding proteins, and induction of an insulin-like growth factor binding protein 3 protease. Crit Care Med 1996, 24:1460-1466.

46. Jeschke MG, Einspanier R, Klein D, Jauch KW: Insulin attenuates the systemic inflammatory response to thermal trauma. Mol Med 2002, 8:443-450.

47. Jeschke MG, Klein D, Herndon DN: Insulin treatment improves the systemic inflammatory reaction to severe trauma. Ann Surg 2004, 239:553-560

48. Don BR, Kaysen G: Serum albumin: relationship to inflammation and nutrition. Semin Dial 2004, 17:432-437.

49. Wolfe RR: Regulation of skeletal muscle protein metabolism in catabolic states. Curr Opin Clin Nutr Metab Care 2005, 8:61-65.

50. Flakoll PJ, Hill JO, Abumrad NN: Acute hyperglycemia enhances proteolysis in normal man. Am J Physiol 1993, 265:E715-E721.

51. Whyte MB, Jackson NC, Shojaee-Moradie F, Treacher DF, Beale RJ, Jones RH, Umpleby AM: Metabolic effects of intensive insulin therapy in critically ill patients. Am J Physiol Endocrinol Metab 2010, 298:E697-E705.

52. Boulétreau P, Chassard D, Allaouchiche B, Dumont JC, Auboyer C, BertinMaghit M, Bricard H, Ecochard R, Rangaraj J, Chambrier C, Schneid C, Cynober L: Glucose-lipid ratio is a determinant of nitrogen balance during total parenteral nutrition in critically ill patients: a prospective, randomized, multicenter blind trial with an intention-to-treat analysis. Intensive Care Med 2005, 31:1394-1400.

53. Wiener RS, Wiener DC, Larson RJ: Benefits and risks of tight glucose control in critically ill adults: a meta-analysis. JAMA 2008, 300:933-944.

doi:10.1186/cc11299

Cite this article as: Hsu et al:: Moderate glucose control results in less negative nitrogen balances in medical intensive care unit patients: a randomized, controlled study. Critical Care 2012 16:R56.

\section{Submit your next manuscript to BioMed Central and take full advantage of:}

- Convenient online submission

- Thorough peer review

- No space constraints or color figure charges

- Immediate publication on acceptance

- Inclusion in PubMed, CAS, Scopus and Google Scholar

- Research which is freely available for redistribution

Submit your manuscript at www.biomedcentral.com/submit 